\title{
Uma educação geométrica apresentada no Boletim Gepem (1976-2010)
}

\section{Marinez Meneghello Passos}

Universidade Estadual de Londrina / UEL - Departamento de Matemática

marinezmp@sercomtel.com.br

\section{Edelaine Cristina de Andrade ${ }^{1}$}

Programa de Pós-Graduação em Ensino de Ciências e Educação Matemática - UEL edelaineandrade@bol.com.br

\author{
Sergio de Mello Arruda ${ }^{2}$ \\ Universidade Estadual de Londrina / UEL - Departamento de Física \\ renop@uel.br
}

\begin{abstract}
Resumo
Este artigo apresenta resultados de uma investigação que tem por objetivo identificar e analisar os artigos que trazem a geometria como foco e que foram publicados entre 1976 e 2010 no Boletim Gepem. Para a constituição do corpus, utilizamos os procedimentos metodológicos da análise textual discursiva. Foram analisados 455 artigos, dos quais 93 foram selecionados. Entre as considerações conclusivas propiciadas por esta análise destacamos que essas produções buscaram enfatizar a importância da geometria apresentando para isso listagens de conteúdos fundamentais que deveriam ser trabalhados com alunos da educação básica e com professores em formação inicial e continuada. Além disso, também trouxeram em suas propostas relações de atividades que poderiam ser utilizadas nessas e em outras situações de ensino.
\end{abstract}

Palavras-chave: Boletim Gepem. Geometria. Análise textual discursiva.

\section{A geometric education presented in the Gepem Bulletin (1976-2010)}

\begin{abstract}
This article presents results of a research that aims to identify and analyze the papers that focuses on geometry and that were published between 1976 and 2010 in the Gepem Bulletin. To build the corpus we used the methodological procedures of discursive textual analysis. We analyzed 455 articles, of which 93 were selected. Among the conclusions afforded by this analysis we highlight that these productions sought to emphasize the importance of geometry presenting a listing of contents that must to be worked with elementary education students and teachers in initial and continuing training. Besides, it also brought in their proposals relations of activities that could be used in these and other teaching situations.
\end{abstract}

Keywords: Gepem Bulletin. Geometry. Discursive textual analysis.

1. Com o apoio da Capes.

2. Com o apoio do CNPq. 


\section{Introdução}

A geometria é um ramo da matemática importante tanto como objeto de estudo quanto como instrumento para outras áreas. Tem por elemento o estudo do espaço e das formas (planas e espaciais) com as suas propriedades. Para se justificar a importância da geometria, bastaria o contexto de que tem função essencial na formação dos indivíduos, pois permite uma interpretação mais completa do mundo, uma comunicação mais abrangente de ideias e uma visão mais equilibrada da matemática (LORENZATO, 1995).

O estudo da geometria é enfatizado pelos Parâmetros Curriculares Nacionais (PCN) como sendo um "campo fértil para trabalhar com situações-problema" (BRASIL, 1998, p.51), assunto costumeiramente de interesse natural dos alunos. A atividade com elementos geométricos favorece a "aprendizagem de números e medidas, pois estimula o aluno a observar, perceber semelhanças e diferenças, identificar regularidades etc." (BRASIL, 1998, p.51).

E ainda, conforme Fainguelernt (1995), a geometria "exerce papel primordial no ensino" (p.46), pois ativa as construções mentais na passagem de dados concretos e experimentais para os processos de abstração e generalização. Além disso, é tema integrador entre as diversas partes da matemática, assim como um "campo fértil para o exercício de aprender a fazer e aprender a pensar" (FAINGUELERNT, 1995, p.46), em que a intuição, o formalismo, a abstração e a dedução são representantes de sua essência.

O levantamento que culminou na produção deste artigo é parte integrante de uma busca investigativa sobre pesquisas desenvolvidas na área de Educação Matemática e que possuem a geometria como temática.

Neste momento, trazemos alguns resultados provenientes de um processo analítico que teve por acervo as 57 revistas editadas entre os anos de 1976 e 2010 no periódico Boletim Gepem $^{3}$ de âmbito nacional da área de Educação Matemática. Este periódico é o mais antigo da área, sua primeira edição é datada do ano de 1976, tendo desde o início o objetivo de ser um espaço de publicação das produções e reflexões de um grupo de estudo e de pesquisa da área de Educação Matemática. Além disso, esse Boletim tornou-se durante essas mais de três décadas de edição um veículo de divulgação de artigos ou comunicações de experiência que viabilize o progresso da Educação Matemática ou a permuta de conhecimentos e ideias entre pesquisadores, educadores e professores de Matemática ${ }^{4}$.

3. Informações retiradas do site do Boletim Gepem. Disponível em: <http://www.Gepem.ufrrj.br/paginas/home.php?id=Historico/>. Acesso em: $30 \mathrm{dez} .2012$.

4. Informações retiradas do site do Boletim Gepem. Disponível em: <http://www.ufrrj.br/SEER/index. php?journal=Gepem\&page=about\&op=editorialPolicies\#custom-1>. Acesso em: 30 dez. 2012. 
Para a escolha do periódico analisado utilizamos o Sistema de Avaliação e Qualificação da Coordenação de Aperfeiçoamento de Pessoal de Nível Superior Capes, o Qualis, e selecionamos o periódico (de circulação nacional) mais antigo da área de Ensino de Educação Matemática, na ocasião da seleção com avaliação nível B1. Em desenvolvimentos futuros pretende-se analisar outros periódicos 'qualisados' com níveis A e B.

A pesquisa realizada é de cunho bibliográfico com características de um "estado da arte". Pesquisas com esses objetivos justificam-se por fazerem um balanço da área do conhecimento escolhida pelos pesquisadores, com a finalidade de reconhecer temáticas de relevância, organizar as informações e localizar lacunas a serem pesquisadas, com a possibilidade de promoverem a evolução das pesquisas em relação ao assunto em pauta. Segundo Romanowski e Ens (2006, p.41), “esses estudos possibilitam uma visão geral do que vem sendo produzido na área e uma ordenação que permite aos interessados perceberem a evolução das pesquisas, bem como suas características e foco".

$\mathrm{Na}$ busca por informações para a constituição de um corpus ${ }^{5}$, partimos da leitura completa de cada um dos artigos do periódico do Gepem e selecionamos aqueles que traziam a geometria como disciplina a ser estudada, como disciplina ofertada em cursos ou como componente de um currículo, em situações de ensino e de aprendizagem em ambientes computacionais, como mote para a discussão das lacunas pertinentes ao ensino da geometria, ou ainda no relato e na discussão de intervenções que possuem essa disciplina como eixo de desenvolvimento.

Desde a década de 80 (do século passado) percebe-se que o ensino da geometria possui lacunas e essa problemática foi analisada por alguns pesquisadores. Segundo Andrade (2011, p.47) é possível perceber três causas principais para o abandono do ensino da geometria no Brasil e em outros países: "O abandono da geometria no período do Movimento da Matemática Moderna; a ausência ou a pouca frequência desta temática nos cursos de formação dos professores e a supressão da demonstração geométrica nos livros didáticos”.

Diante desta constatação e das problemáticas relacionadas ao ensino da geometria - criamos uma linha de atuação em nosso grupo de pesquisa que se debruça sob tais reflexões. O que nos leva a realizar esses levantamentos, idealizando construir um "estado da arte" relacionado à geometria, é o fato de que eles podem contribuir com a evidenciação de quais aspectos e dimensões estão sendo destacados e privilegiados pela área de Educação Matemática no que diz respeito à geometria como campo de estudo e de pesquisa.

5. É o conjunto dos documentos tidos em conta para serem submetidos aos procedimentos analíticos (BARDIN, 2004, p.90). 
Foi realizado o estudo de 57 exemplares do periódico, perfazendo um total de 455 itens, entre eles, artigos, relatos de experiência, informativos, resenhas, indicações para aula, atividades promovidas pelo Boletim do Gepem, relatórios da secretaria do Gepem, notícias, tradução de carta, olimpíadas, curiosidades, desafios, resoluções de problemas apresentados no periódico anterior, notas de aulas, sugestões para sua aula, homenagens.

Como resultado desse movimento de leitura e tendo em mente os objetivos de pesquisa, tomamos a decisão em trazer para constituir o corpus investigativo, somente os artigos e os relatos de experiência. Algumas informações sobre eles podem ser observadas no Quadro 1.

\begin{tabular}{|c|c|c|c|c|}
\hline $\begin{array}{l}\text { Números dos } \\
\text { exemplares }\end{array}$ & Período de publicação & $\begin{array}{l}\text { Quantidade } \\
\text { total de itens } \\
\text { analisados }\end{array}$ & $\begin{array}{c}\text { Quantidade de } \\
\text { artigos / relatos } \\
\text { de experiência } \\
\text { encontrados }\end{array}$ & $\begin{array}{c}\text { Quantidade de } \\
\text { artigos / relatos } \\
\text { de experiência } \\
\text { selecionados }\end{array}$ \\
\hline N. 1 a 10 & $\begin{array}{l}\text { 1976-1980 } \\
\text { ( (1976); } 2 \text {, } 3 \text { e } 4 \text { (1977); } 5 \text { e } \\
6 \text { (1978); } 7 \text { e } 8 \text { (1979); } 9 \text { e } 10 \\
\text { (1980) }\end{array}$ & 78 & 43 & 11 \\
\hline N. 11 a 17 & $\begin{array}{l}\mathbf{1 9 8 1 - 1 9 8 5} \\
11 \text { e } 12(1981) ; 13 \text { e } 14 \text { (1982); } \\
15(1983) ; 16(1984) ; 17(1985)\end{array}$ & 46 & 26 & 8 \\
\hline N. 18 a 27 & $\begin{array}{l}1986-1990 \\
18 \text { e } 19 \text { (1986); } 20 \text { e } 21 \text { (1987); } \\
22 \text { e } 23 \text { (1988); } 24 \text { e } 25 \text { (1989); } \\
26 \text { e } 27 \text { (1990) }\end{array}$ & 81 & 60 & 18 \\
\hline N. 28 a 33 & $\begin{array}{l}\text { 1991-1995 } \\
\text { 28 e } 29 \text { (1991); } 30 \text { (1992); } 31 \\
\text { (1993); } 32 \text { (1994); } 33 \text { (1995) }\end{array}$ & 41 & 36 & 12 \\
\hline N. 34 a 37 & $\begin{array}{l}\text { 1998-2000 } \\
34 \text { (1998); } 35 \text { (1999); } 36 \text { e } 37 \\
(2000)\end{array}$ & 36 & 29 & 10 \\
\hline N. 38 a 47 & $\begin{array}{l}2001-2005 \\
38 \text { e } 39(2001) ; 40 \text { (2002); } 41 \\
42 \text { e } 43(2003) ; 44 \text { e } 45 \text { (2004); } \\
46 \text { e } 47(2005)\end{array}$ & 87 & 57 & 15 \\
\hline N. 48 a 57 & $\begin{array}{l}\text { 2006-2010 } \\
48 \text { e } 49 \text { (2006); } 50 \text { e } 51 \text { (2007); } \\
52 \text { e } 53 \text { (2008); } 54 \text { e } 55 \text { (2009); } \\
56 \text { e } 57(2010)\end{array}$ & 86 & 56 & 19 \\
\hline TOTAIS & 35 anos & 455 & 307 & 93 \\
\hline
\end{tabular}

Quadro 1: Informações quantitativas sobre os itens analisados e selecionados para pesquisa 
No Quadro 1 a acomodação e a descrição das informações foram realizadas em ordem crescente de data, ou seja, das publicações mais antigas para as mais recentes e agrupadas por quinquênio. Na primeira coluna pode-se observar o número das revistas neste período, na segunda coluna temos especificamente a delimitação de cada quinquênio, o número do periódico e ano de sua publicação: 1 (1976), representa o exemplar de número 1 e o ano em que foi publicado; 2, 3 e 4 (1977) representam os exemplares de número 2, 3 e 4 publicados no ano de 1977. Na terceira coluna destacamos a quantidade total de itens analisados nos 57 exemplares do periódico - acomodados por quinquênio e na quarta e quinta colunas foram apresentadas as quantidades totais dos artigos e dos relatos de experiência encontrados e selecionados, respectivamente. Na última linha do Quadro temos a quantificação dos itens localizados nesses 35 anos de publicação, com um total de 455 itens analisados, sendo que 307 desses itens correspondem a artigos e a relatos, dos quais 93 passaram a construir nosso corpus. Lembrando que para esta investigação buscamos por artigos e relatos de experiência que trouxessem informações relativas à temática geometria.

\section{A coleta de dados e a metodologia assumida}

De acordo com Moraes e Galiazzi (2007), percebe-se o aumento do número de pesquisas qualitativas que se utilizam de análises textuais. Essa análise pode ser realizada assumindo por objeto de estudo textos já existentes ou textos que serão produzidos por meio de entrevistas e de observações, especificamente, para a pesquisa.

De posse desta metodologia, objetiva-se aprofundar a concepção daquilo que está sendo apresentado no material, não havendo o intuito de testar hipóteses, comprovando-as ou rejeitando-as ao término da pesquisa, ou seja, a "intenção é a compreensão, reconstruir conhecimentos existentes sobre os temas investigados" (MORAES e GALIAZZI, 2007, p.11).

Assumido o referencial analítico, as informações derivadas de nossa coleta de dados foram submetidas à metodologia da análise textual discursiva, que se constitui inicialmente das seguintes etapas: a desmontagem dos textos em interpretação, do estabelecimento de relações entre os textos e entre as unidades de registro delimitadas e da captura de um 'novo' emergente, ou seja, de compreensões possibilitadas diante dos procedimentos metodológicos assumidos. A segunda fase desse processo analítico é constituída por "um processo auto-organizado" (MORAES e GALIAZZI, 2007, p.11-12) que procura evidenciar categorias que possam retratar o fenômeno em estudo e auxiliar na composição de uma 
comunicação a respeito do emergente, dos achados segundo a visão do pesquisador - esta comunicação recebe a denominação de metatexto ${ }^{6}$.

Cabe destacar, segundo os autores que nos apresentam a análise textual discursiva, que um mesmo texto pode proporcionar uma diversidade de sentidos, podendo, sua interpretação, estar circunstanciada pela intenção que o pesquisador apresenta em relação ao texto, pelos referenciais que o acompanham no desenvolvimento da abordagem investigativa e pelas interpretações dos sentidos que os termos que compõem o texto podem oferecer, ou seja, a "análise textual propõe-se a descrever e interpretar alguns dos sentidos que a leitura de um conjunto de textos pode suscitar".

Diante dessas argumentações e após a leitura integral dos artigos em busca da evidência da temática geometria, vimos a necessidade de retomar os artigos e relatos de experiência selecionados e destacar as palavras e/ou expressões que faziam parte dos artigos como um todo e que se mostravam significativas quanto ao objetivo maior da pesquisa - um inventário relativo ao que se apresentava sobre geometria nesses 35 anos de publicação do Boletim Gepem.

Cientes de que todo processo de análise textual discursiva gira em torno da produção do metatexto e que é a partir da unitarização e categorização que se constrói a estrutura básica do metatexto (MORAES e GALIAZZI, 2007, p.14), passamos para uma segunda fase interpretativa da investigação, a categorização. Procedimento relacionado a uma forma de agrupar as inúmeras informações que se destacam como fundamentais para os avanços das compreensões almejadas.

$\mathrm{Na}$ sequência trazemos algumas informações quantitativas referentes a esses procedimentos e as conclusões a que essa investigação nos remete.

\section{A quantificação e a relação das produções analisadas}

Posteriormente à seleção dos artigos investimos na apresentação de um estudo quantitativo sobre a geometria, analisando-os e buscando observar o que nossos achados nos apresentavam.

Uma das primeiras percepções foi que essa temática começou a ser divulgada nesse periódico desde o seu número 1 (1976) e que as produções sobre esse assunto mantiveram-se em todos os quinquênios com certa representatividade -

6. Moraes e Galiazzi (2007) descrevem metatexto como: "Expressão por meio da linguagem das principais ideias emergentes das análises e apresentação dos argumentos construídos pelo pesquisador em sua investigação, capaz de comunicar a outros as novas compreensões atingidas" (MORAES e GALIAZZI, 2007, p.94). 
variando entre 8 e 19 produções para cada 5 anos. No Gráfico 1 é possível observar tais informações?

\section{Total de artigos/relatos de experiência}

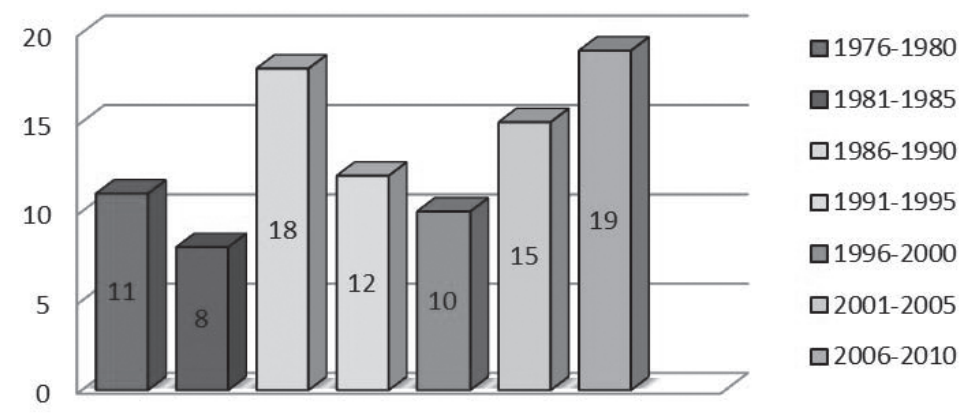

Gráfico 1 - Publicações que trazem a temática geometria no Boletim Gepem de 1976 a 2010

Após essa descrição dos artigos / relatos por meio do Gráfico 1 pode-se evidenciar que a primeira publicação, em 1976, fazia referência à geometria. Notamos também que houve uma constância na publicação e que no terceiro quinquênio (1986-1990) e no último (2006-2010), encontramos o maior número de publicações referentes ao tema em estudo.

Destacamos neste momento que o Boletim Gepem de número 48 (2006) apresenta um estudo sobre todos os artigos e relatos publicados em seus 30 anos (número denominado comemorativo por seus editores). Nesse estudo, os autores estabeleceram grupos para organizar o material que estavam analisando: temática, nível ou interesse educativo, elementos conceituais ou curriculares e contexto formativo. No grupo “temática” foram acomodados (naquela ocasião) conteúdos matemáticos: álgebra, análise, aritmética, estatística/probabilidade/tratamento da informação, funções, geometria, lógica, matemática discreta, topologia, tema geral. No item "nível ou interesse educativo", os autores reagruparam as produções segundo características relativas a níveis de escolaridade: ensino superior, educação de jovens e de adultos, educação especial, formação de professores e

7. Cabe sublinhar que mesmo com a edição temática de número 32 (ano 1994) sobre geometria não houve uma discrepância em relação à quantidade de artigos relativos ao assunto no quinquênio relacionado. Por esse motivo, não interpretamos de outra forma as informações coletadas, ou seja, mantivemos o padrão assumido para todo o acervo. 
educação básica. Para acomodar as informações segundo os "elementos conceituais ou curriculares" foram destacados os temas: etnomatemática, interdisciplinaridade, jogos, recursos didáticos, resolução de problemas, temas transversais e outras abordagens. Para o grupo "contexto formativo" foram identificados artigos voltados para os estudos presenciais, a distância ou semipresencial, não especificado (OLIVEIRA et al., 2006, p.26).

Para nossa análise, consideramos o que foi apresentado neste Boletim de número 48, contudo destacamos que um único artigo apontado por eles como pertinente à temática geometria não faz parte do nosso corpus de estudo - Logo no ensino de $1^{\circ}$ grau $-4^{\mathrm{a}}$ a $8^{\mathrm{a}}$ série - justificamos a não inclusão pelo fato de que o conteúdo do artigo enfatiza o Logo como uma linguagem de programação, sem destaque ao contexto e ao desenvolvimento do pensamento geométrico que ele possibilita. Todavia, quando observamos a nossa lista de artigos selecionados (exemplares de n.1 até n.47) e comparamos com os destacados no Boletim 48 em nossa seleção consideramos 74 artigos em contraposição a 46 indicados por Oliveira et al. Mais uma vez nos colocamos em situação de justificação - tomando alguns exemplos para sustentar nosso movimento: o item 24 pertencente à nossa lista destaca 'Euclides e entes geométricos' em sua discussão sobre a matemática e a linguagem (por isso foi considerado); o item 26 traz atividades relativas à geometria vinculada a "uma experiência em Educação Matemática"; o item 29 apresenta alguns aspectos de 'ideias fundamentais da matemática moderna' e destaca as geometrias não euclidianas e a axiomatização na geometria (motivo que nos levou a selecioná-lo). As justificativas aqui apresentadas para estes três itens poderiam ser estendidas para os 28 artigos que fazem parte do nosso corpus analítico e que - no período equivalente - não foram destacados pelos proponentes daquela composição.

Acreditamos que as divergências encontradas nas listagens devem-se ao fato de que para cada caso foram considerados referenciais e perspectivas diferentes de observação e seleção do acervo, e, por conseguinte, da constituição do corpus para estudo e análise. Com certeza a busca pela questão que gerou cada investigação materializada na forma de artigo, bem como o produto dessa pesquisa, baliza de outra forma as categorizações, sempre fundamentais nesses contextos de pesquisa.

$\mathrm{Na}$ sequência listamos os 93 artigos/relatos selecionados - organizando-os por ano de publicação e destacando ao final e entre parênteses o número do exemplar em que podem ser localizados. 


\begin{tabular}{|c|c|}
\hline ANO & $\begin{array}{l}\text { Artigo/relato de experiência com as palavras e expressões que remetem à } \\
\text { geometria }\end{array}$ \\
\hline 1976 & 1. Matemática no ensino pré-escolar. LOPES, Maria Laura Mouzinho Leite. (n.1) \\
\hline \multirow[t]{3}{*}{1977} & $\begin{array}{l}\text { 2. O ensino no Estado do Rio de Janeiro. QUEIROZ, Amelia Maria Noronha Pessoa. } \\
\text { (n.2) }\end{array}$ \\
\hline & $\begin{array}{l}\text { 3. Situação do Ensino da matemática no Estado da Bahia. DANTAS, Martha Maria de } \\
\text { Souza. (n.2) }\end{array}$ \\
\hline & $\begin{array}{l}\text { 4. Justificativa de um currículo de matemática para o ensino pré-escolar (4-7 anos). } \\
\text { LOPES, Maria Laura Mouzinho Leite. (n.3) }\end{array}$ \\
\hline 1978 & $\begin{array}{l}\text { 5. Séries didáticas de matemática - audiovisual. FAINGUELERNT, Estela Kaufman. } \\
\text { (n.6) }\end{array}$ \\
\hline \multirow[t]{2}{*}{1979} & $\begin{array}{l}\text { 6. Algumas observações feitas em classe a propósito do desenvolvimento do cubo } \\
\text { I.R.E.M. - Montpellier. GROUPE RECHERCHE GEOMETRIE. (n.7) }\end{array}$ \\
\hline & $\begin{array}{l}\text { 7. A geometria da teoria da relatividade de Einstein. SANTOS, Christovam Colombo } \\
\text { (n.8). }\end{array}$ \\
\hline \multirow[t]{4}{*}{1980} & 8. Sobre uma "Geometria de quatro pontos". CARVALHO, Moema Sá. (n.9) \\
\hline & $\begin{array}{l}\text { 9. A formação do professor e a melhoria da educação matemática. FEHR, Howard. } \\
\text { Tradução: Amélia Maria Noronha Pessoa de Queiroz. (n.9) }\end{array}$ \\
\hline & $\begin{array}{l}\text { 10. O ensino da geometria no espaço para alunos do } 2^{\circ} \text { grau. CALADO, Helenalda } \\
\text { Nazareth; LIBERMAN, Manhucia; PAVANELLO, Regina Maria. (n.10) }\end{array}$ \\
\hline & $\begin{array}{l}\text { 11. Comentários sobre educação matemática. PIAGET, Jean. Tradução: Leila Alcure. } \\
\text { (n.10) }\end{array}$ \\
\hline \multirow[t]{3}{*}{1981} & $\begin{array}{l}\text { 12. Binômio professor-aluno na iniciação à educação matemática. BORDEAUX, Ana } \\
\text { Lúcia; et al. Coordenador Geral: Maria Laura Leite Lopes. (n.11) }\end{array}$ \\
\hline & $\begin{array}{l}\text { 13. Um modelo matemático para o estudo das dificuldades apresentadas pelos alunos do } \\
2^{\circ} \text { grau na resolução de sistemas lineares. FAINGUELERNT, Estela Kaufman. (n.12) }\end{array}$ \\
\hline & $\begin{array}{l}\text { 14. Curso de geometria elementar. IMENES, Luiz Márcio; JAKUBOVIC, José; } \\
\text { TROTTA, Fernando. (1981, n.12) }\end{array}$ \\
\hline \multirow[t]{3}{*}{1982} & $\begin{array}{l}\text { 15. Reforma do ensino da geometria. FEHR, Howard F. Tradução: Moema Sá Carvalho. } \\
(1982, \text { n.13) }\end{array}$ \\
\hline & $\begin{array}{l}\text { 16. Estruturas algébricas. QUEIROZ, Amélia Maria Noronha Pessoa; RUBINSTEIN, } \\
\text { Cléa; MONKEN, Regina Célia; RODRIGUES, Vera Maria Ferreira. (n.13) }\end{array}$ \\
\hline & $\begin{array}{l}\text { 17. Sobre o ensino da geometria. BKOUCHE, Rudolph; LILLE, Irem. Tradução: Vera } \\
\text { Maria Ferreira Rodrigues. (n.14) }\end{array}$ \\
\hline 1983 & 18. Sobre o ensino da geometria. LOPES, Maria Laura M. Leite. (n.15) \\
\hline 1985 & 19. $6^{\text {a }}$ Olimpíada estadual de matemática/RJ. Autor: não identificado. (n.17) \\
\hline
\end{tabular}




\begin{tabular}{|c|c|}
\hline \multirow[t]{3}{*}{1986} & $\begin{array}{l}\text { 20. Pós-graduação em educação matemática, a experiência de Rio Claro. DANTE, Luiz } \\
\text { Roberto. (n.18) }\end{array}$ \\
\hline & 21. Aconteceu comigo. SOUZA, Eloi Tavares. (n.18) \\
\hline & $\begin{array}{l}\text { 22. Ensino da matemática - um processo entre a exposição e a descoberta. DANTAS, } \\
\text { Martha de Souza. (n.19) }\end{array}$ \\
\hline \multirow[t]{5}{*}{1987} & 23. O ensino da geometria no $1^{\circ}$ grau. Grupo Momento. (n.20) \\
\hline & 24. A matemática e a linguagem. QUEIROZ, Amélia Maria Noronha Pessoa de. (n.21) \\
\hline & 25. A geometria dos mosaicos. IMENES, Luiz Márcio. (n.21) \\
\hline & $\begin{array}{l}\text { 26. Uma experiência em educação matemática desenvolvida na Universidade de } \\
\text { Pernambuco. Reportagens João Barbosa de Oliveira, Maristela Jorge Melo e Teresa } \\
\text { Emília Aquino de Lima - Diário de Pernambuco. (n.21) }\end{array}$ \\
\hline & 27. Jogo matemático. AVERBUCK, Anna; GOTTLIEB, Franca Cohen. (n.21) \\
\hline \multirow[t]{3}{*}{1988} & $\begin{array}{l}\text { 28. Resolução de problemas de matemática elementar. DINIZ, Maria Ignez de Souza V. } \\
\text { (n.22) }\end{array}$ \\
\hline & $\begin{array}{l}\text { 29. As ideias fundamentais da matemática moderna. CARVALHO, João Bosco } \\
\text { Pitombeira de. (n.23) }\end{array}$ \\
\hline & 30. Olimpíada Estadual de Matemática. Autor: não identificado. (n.23) \\
\hline \multirow[t]{3}{*}{1989} & $\begin{array}{l}\text { 31. Um método geral para construir polígonos regulares, inspirado numa técnica } \\
\text { moçambicana de entrelaçamento. GERDES, Paulus. (n.24) }\end{array}$ \\
\hline & $\begin{array}{l}\text { 32. Matemática moderna, sua origem e aspectos de seu desenvolvimento em alguns } \\
\text { países ocidentais. KALEFF, Ana Maria M. R. (n.25) }\end{array}$ \\
\hline & 33. Sobre uma propriedade métrica do paralelogramo. MEDEIROS, Luiz Adauto. (n.25) \\
\hline \multirow[t]{4}{*}{1990} & 34. Ideias fundamentais da matemática. CARVALHO, João Bosco Pitombeira de. (n.26) \\
\hline & $\begin{array}{l}\text { 35. Técnica moderna para o ensino da matemática - técnica para o ensino de caráter } \\
\text { construtivo. AVERBUCH, Anna; GOTTLIEB, Franca Cohen. (n.27) }\end{array}$ \\
\hline & $\begin{array}{l}\text { 36. Translações e simetrias no plano. FAINGUELERNT, Estela Kaufman; } \\
\text { BORDINHÃO, Noelir de Carvalho. (n.27) }\end{array}$ \\
\hline & 37. O desenvolvimento do raciocínio em geometria. NASSER, Lilian. (n.27) \\
\hline \multirow[t]{2}{*}{1991} & 38. Razão matemática x argumentação. PESSANHA, José Américo Motta. (n.28) \\
\hline & $\begin{array}{l}\text { 39. Níveis de Van Hiele: uma explicação definitiva para as dificuldades em geometria? } \\
\text { NASSER, Lilian. (n.29) }\end{array}$ \\
\hline 1992 & 40. Sobre a origem histórica do conceito de número. GERDES, Paulus. (n.30) \\
\hline
\end{tabular}




\begin{tabular}{|c|c|}
\hline \multirow[t]{2}{*}{1993} & $\begin{array}{l}\text { 41. A importância do ensino da geometria na formação do educador matemático. } \\
\text { KALEFF, Ana Maria Roland. (n.31) }\end{array}$ \\
\hline & $\begin{array}{l}\text { 42. A importância da argumentação na construção do conceito de altura de triângulo. } \\
\text { SILVA, Maria Solange. (n.31) }\end{array}$ \\
\hline \multirow[t]{5}{*}{1994} & $\begin{array}{l}\text { 43. Aspectos psicológicos de aprendizagem da geometria. HERSHKOWITZ, Rina com } \\
\text { a colaboração de Bem-Chaim, Celia Hoyles, Glenda Lappan, Michael Mitchelmore, } \\
\text { Shlomo Vinner. (n.32) }\end{array}$ \\
\hline & 44. Fundamento e concepção do projeto Agam. HERSHKOWITZ, Rina. (n.32) \\
\hline & $\begin{array}{l}\text { 45. Visualização em geometria - as duas faces da moeda. HERSHKOWITZ, Rina. } \\
\text { (n.32) }\end{array}$ \\
\hline & $\begin{array}{l}\text { 46. Atividades com professores baseadas em pesquisas cognitivas. HERSHKOWITZ, } \\
\text { Rina; BRUCKHELMER, Maxim; VINNER, Shlomo. (n.32) }\end{array}$ \\
\hline & $\begin{array}{l}\text { 47. LOCI e pensamento visual. HERSHKOWITZ, Rina; FRIENDLANDER, Alex; } \\
\text { DREYFUS, Tommy. (n.32) }\end{array}$ \\
\hline \multirow[t]{2}{*}{1995} & 48. Intuição e proporcionalidade. VALLADARES, Renato J. C. (n.33) \\
\hline & $\begin{array}{l}\text { 49. A prática de ensino e a formação do professor de matemática. FAINGUELERNT, } \\
\text { Estela Kaufman. (n.33) }\end{array}$ \\
\hline \multirow[t]{3}{*}{1998} & 50. Revisitando a raiz quadrada. VIANA, Vera Lúcia Fazoli da Cunha Freitas. (n.34) \\
\hline & 51. Semelhança na $7^{\mathrm{a}}$ série: algumas dificuldades. BAIRRAL, Marcelo Almeida. (n.34) \\
\hline & $\begin{array}{l}\text { 52. O papel da argumentação no ensino da geometria: um estudo de caso. SILVA, Maria } \\
\text { Solange da. (n.34) }\end{array}$ \\
\hline \multirow[t]{3}{*}{1999} & $\begin{array}{l}\text { 53. Construindo o conceito de simetria em relação a uma reta: do jardim de infância ao } \\
\text { ensino superior. KALEFF, Ana Maria M. R. (n.35) }\end{array}$ \\
\hline & $\begin{array}{l}\text { 54. Inequação: a construção de seu significado. FAINGUELERNT, Estela K.; } \\
\text { GOTTLIEB, Franca Cohen; MARINHOS, Alzir Fourny. (n.35) }\end{array}$ \\
\hline & $\begin{array}{l}\text { 55. A matemática e a geometria nas leis de Kepler e da gravidade. VALLADARES, } \\
\text { Renato José da Costa. (n.35) }\end{array}$ \\
\hline \multirow[t]{4}{*}{2000} & $\begin{array}{l}\text { 56. Tecnologia e avaliação: um olhar através dos parâmetros curriculares nacionais do } \\
\text { ensino médio. PAUPITZ, Selma Kozel. (n.37) }\end{array}$ \\
\hline & 57. Un club para recrear la matemática. VEJA, María Luz Callejo de la. (n.37) \\
\hline & $\begin{array}{l}\text { 58. Didática da matemática e a atuação pioneira de Georges Glaeser. LOPES, Maria } \\
\text { Laura Mouzinho Leite. (n.37) }\end{array}$ \\
\hline & $\begin{array}{l}\text { 59. Rupturas no estatuto matemático dos números negativos. SCHUBRING, Gert. } \\
\text { Tradução: Rosa M. Mazo Reis. (n.37) }\end{array}$ \\
\hline
\end{tabular}




\begin{tabular}{|c|c|}
\hline \multirow[t]{4}{*}{2001} & $\begin{array}{l}\text { 60. A educação matemática na Universidade Federal Fluminense: um relato do } \\
\text { desenvolvimento histórico dos cursos de formação de professores de matemática. } \\
\text { KALEFF, Ana Maria Roland. (n.38) }\end{array}$ \\
\hline & $\begin{array}{l}\text { 61. Rupturas no estatuto matemático dos números negativos. SCHUBRING, Gert. } \\
\text { Tradução de José Paulo Q. Carneiro e Rosa M. Mazo Reis. (n.38) }\end{array}$ \\
\hline & $\begin{array}{l}\text { 62. Desenvolvimento profissional docente baseado na WEB: perspectivas para a } \\
\text { educação geométrica. BAIRRAL, Marcelo Almeida; RODRIGUEZ, Joaquim Giménez; } \\
\text { TOGASHI, Emílio Makoto. (n.39) }\end{array}$ \\
\hline & $\begin{array}{l}\text { 63. Investigando e justificando problemas geométricos com o Cabri-géomètre II. } \\
\text { BARBOSA, Andreia Carvalho Maciel. (n.39) }\end{array}$ \\
\hline 2002 & $\begin{array}{l}\text { 64. Criando, vendo e entendendo sólidos de revolução. KALEFF, Ana Maria; SÁ, } \\
\text { Luciana Almeida; TOLEDO Maria Inês Martins de. (n.40) }\end{array}$ \\
\hline \multirow[t]{5}{*}{2003} & $\begin{array}{l}\text { 65. Educação algébrica e a resolução de problemas: a proposta de interatividade do salto } \\
\text { para o futuro. CASTRO, Monica Rabello de. (n.42) }\end{array}$ \\
\hline & $\begin{array}{l}\text { 66. Álgebra, geometria e aritmética de mãos dadas no ensino fundamental. GOMES, } \\
\text { Maria da Conceição Vieira. (n.42) }\end{array}$ \\
\hline & $\begin{array}{l}\text { 67. Uma introdução ao estudo de funções utilizando softwares educativos. BARBOSA, } \\
\text { Andreia Carvalho Maciel. (n.42) }\end{array}$ \\
\hline & $\begin{array}{l}\text { 68. Argumentações, linguagens e procedimentos em tarefas de geometria. ARAUJO, } \\
\text { Jaqueline. (n.43) }\end{array}$ \\
\hline & $\begin{array}{l}\text { 69. Como o surpreendente Arquimedes determinou o volume e a área da esfera. } \\
\text { ESQUEF, Paulo Antonio. (n.43) }\end{array}$ \\
\hline \multirow[t]{3}{*}{2004} & $\begin{array}{l}\text { 70. Atividades introdutórias às geometrias não euclidianas: o exemplo da geometria do } \\
\text { Táxi. KALEFF, Ana Maria Roland; NASCIMENTO, Rogério Santos do. (n.44) }\end{array}$ \\
\hline & $\begin{array}{l}\text { 71. Ambiguidade e metonímia nas aulas de matemática do ensino fundamental e médio. } \\
\text { NOVAES, José Antônio. (n.44) }\end{array}$ \\
\hline & $\begin{array}{l}\text { 72. Sobre o poder de algumas palavras e imagens quando se busca avançar além das } \\
\text { noções euclidianas mais comuns. KALEFF, Anna Maria Martensen Roland. (n.45) }\end{array}$ \\
\hline \multirow[t]{2}{*}{2005} & $\begin{array}{l}\text { 73. Uma via estética de acesso ao conhecimento matemático. CIFUENTES, José Carlos. } \\
\text { (n.46) }\end{array}$ \\
\hline & $\begin{array}{l}\text { 74. A dimensão instigante da leitura na formação de professores de matemática. PAIVA, } \\
\text { Ana Maria Severiano de, et al. (n. } 46 \text { ) }\end{array}$ \\
\hline \multirow[t]{2}{*}{2006} & $\begin{array}{l}\text { 75. Um estudo sobre a educação matemática publicada nos } 30 \text { anos do Boletim Gepem. } \\
\text { OLIVEIRA, Rosana de; BAIRRAL, Marcelo Almeida; REIS, Rosa Maria Mazo. (n.48) }\end{array}$ \\
\hline & $\begin{array}{l}\text { 76. Professores de matemática que utilizam tecnologia informática em sua atividade } \\
\text { docente. ZULATTO, Rúbia Barcelos Amaral; PENTEADO, Miriam Godoy. (n.49) }\end{array}$ \\
\hline
\end{tabular}




\begin{tabular}{|c|c|}
\hline \multirow[t]{2}{*}{2007} & $\begin{array}{l}\text { 77. Brincando com a Torre de Hanói e descobrindo fractais: uma sugestão de atividade } \\
\text { para o ensino médio. NINA, Clarissa Trojack Della. (n.50) }\end{array}$ \\
\hline & $\begin{array}{l}\text { 78. A história da matemática na educação matemática de futuros professores: o problema } \\
\text { de quadraturas. CYRINO, Márcia Cristina de Costa T.; CORRÊA, Júlio Faria. (n.51) }\end{array}$ \\
\hline \multirow[t]{5}{*}{2008} & $\begin{array}{l}\text { 79. A matemática na escola dos sem-terra: uma abordagem etnomatemática. RICHIT, } \\
\text { Adriana; TOMKELSKI, Mauri Luís. (n.52) }\end{array}$ \\
\hline & $\begin{array}{l}\text { 80. Trabalho colaborativo mediado pelas tecnologias de informação e comunicação na } \\
\text { formação do professor de matemática: indícios de mudança da cultura docente. COSTA, } \\
\text { Gilvan Luiz Machado. (n.52) }\end{array}$ \\
\hline & $\begin{array}{l}\text { 81. Relato de uma implementação de uma disciplina de Cálculo na arquitetura. PALIS, } \\
\text { Gilda de La Rocque. (n.52) }\end{array}$ \\
\hline & $\begin{array}{l}\text { 82. Atividades de geometria espacial e tecnologias informáticas no contexto da } \\
\text { educação a distância online. SANTOS, Silvana Claudia. }(2008, n .53)\end{array}$ \\
\hline & $\begin{array}{l}\text { 83. Exploração de trabalhos de Escher em aulas de geometria. NINA, Clarissa Trojack } \\
\text { Della; MENEGASSI, Maria Elvira Jardim; SILVA, Mercedes Matte da. (n.53) }\end{array}$ \\
\hline \multirow[t]{6}{*}{2009} & $\begin{array}{l}\text { 84. Demonstrações em geometria: alunos de licenciatura, ambiente informatizado e } \\
\text { reflexões para a formação do professor de matemática. ROLKOUSKI, Emerson. (n.54) }\end{array}$ \\
\hline & $\begin{array}{l}\text { 85. Transformações lineares planas: um estudo com base nos registros de representações } \\
\text { semióticas e na utilização da geometria dinâmica. KARRER, Monica; JANH, Ana } \\
\text { Paula. (n.55) }\end{array}$ \\
\hline & $\begin{array}{l}\text { 86. Sobre a identidade do Centro de Educação Matemática (CEM): configurações de uma } \\
\text { leitura sociológica. SILVA, Heloisa da; GARNICA, Antonio Vicente Marafioti. (n.55) }\end{array}$ \\
\hline & $\begin{array}{l}\text { 87. A desigualdade triangular: cenários para investigação numa sala de aula de } 6^{\text {a }} \text { série. } \\
\text { TOMAZETTO, Mirian; NACARATO, Adair Mendes. (n.55) }\end{array}$ \\
\hline & $\begin{array}{l}\text { 88. Recontando uma história: o formalismo e o ensino de matemática no Brasil. CURY, } \\
\text { Helena Noronha. (n.55) }\end{array}$ \\
\hline & $\begin{array}{l}\text { 89. Análise combinatória: experiências de sala de aula. NINA, Clarissa Trojack Della; } \\
\text { MENEGASSI, Maria Elvira Jardim; SILVA, Mercedes Matte da. (n.55) }\end{array}$ \\
\hline \multirow[t]{4}{*}{2010} & $\begin{array}{l}\text { 90. Fractais em sala de aula: uma experiência com papel e tesoura, computador e } \\
\text { espelho. PEREIRA, Emerson Luiz; ZULATTO, Rúbia Barcelos Amaral. (2010, n.56) }\end{array}$ \\
\hline & $\begin{array}{l}\text { 91. O geoplano como recurso de aprendizagem da geometria plana para deficientes } \\
\text { visuais: uma experiência com os alunos do Instituto Benjamin Constant. DIAS, Marcelo } \\
\text { de Oliveira; SANTOS, Marcele da Silva. (n.56) }\end{array}$ \\
\hline & $\begin{array}{l}\text { 92. Construindo o conceito de alturas de triângulo com o Cabri-géomètre II: verticalidade } \\
\text { ou perpendicularidade? LEIVAS, José Carlos Pinto; SCHERER, Suely. (n.56) }\end{array}$ \\
\hline & $\begin{array}{l}\text { 93. Um estudo sobre ensino de funções na ótica da proposta curricular do Estado de São } \\
\text { Paulo. JUNIOR, Eduardo M. de Souza; LOPES, Jairo de Araújo. (n. } 57 \text { ) }\end{array}$ \\
\hline
\end{tabular}


Destacamos que em alguns fascículos não houve artigos selecionados como foi o caso dos exemplares de número 4 do ano de 1977, n.5 do ano de 1978, n.16 (1984), n.36 (2000), n.41 (2003) e n.47 (2005). Nos anos de 1996 e 1997 não houve publicação da revista.

\section{O processo interpretativo}

Com o objetivo de compreender o que foi apresentado nas produções selecionadas referente à temática geometria nestes 35 anos de publicação do Boletim Gepem, realizamos um movimento que organizasse as informações que íamos identificando como fundamentais para a análise em curso.

Amparados pelos procedimentos da análise textual discursiva e após diversas leituras - algumas flutuantes e outras em profundidade - optamos pela evidência e possibilidade de agrupamentos segundo algumas unidades interpretativas e que possibilitassem a construção de categorias que sustentassem nossas conclusões. Essas unidades interpretativas foram acomodadas segundo dois critérios - um que evidenciasse o contexto do que era apresentado no artigo/relato de experiência e outro que apresentasse palavras ou expressões que nos possibilitassem reconstituir o artigo com certa facilidade, isto é, palavras ou expressões que nos remetessem a um 'contar o que tínhamos ali apresentado por seus autores'. Deste movimento que denominamos descritivo, constituímos um quadro que possui mais de oito páginas em espaço simples e corpo 10, para a acomodação das informações relacionadas (por ser um arquivo extremamente longo não o incluímos neste artigo). No entanto, trazemos uma exemplificação relativa aos registros nele inseridos: Ano 1976 referindo-se ao ano de publicação do exemplar (primeira coluna e primeira linha com dados); ainda nesta primeira linha, porém na segunda coluna - primeira publicação considerada (1.) acompanhada do título Matemática no ensino pré-escolar; de autoria de Maria Laura M. Leite Lopes; seguida da referência bibliográfica a que pertence esse corpus, ou seja, o Boletim Gepem, ano de publicação do exemplar, número do exemplar e páginas em que se encontra o material selecionado. Na segunda linha do texto que compõe esta célula, apresentamos o contexto do que é apresentado, neste caso, Proposta de atividade e na terceira linha desta mesma célula de organização - as palavras e/ou expressões consideradas significativas para a construção das nossas compreensões. Neste exemplo temos somente a palavra Geometria. Para o item 6 temos para o contexto, novamente, Proposta de atividade e para as palavras e/ou expressões destacadas como importantes relacionamos - Cubo; faces; arestas; base; simétricos; figura plana.

Quando tomamos esse quadro de informações descritivo com os registros dos 93 artigos/relatos - em uma leitura contínua - focando os registros que trazem 
informações relativas ao contexto, verificamos que a importância da geometria, tanto no aprendizado, no estudo, no ensino, no conteúdo, na relação geométrica, na geometria euclidiana, no uso da argumentação, teve fundamental relevância nos artigos considerados nesta pesquisa. O mesmo pode-se dizer da evidenciação e da frequência com que foi destacada a geometria como conteúdo a ser trabalhado e a geometria como proposta de atividade, nestes dois casos, complementados por relações de tópicos que contribuem com a identificação e a descrição de teor do artigo/relato.

Uma interpretação possibilitada durante os estudos desses registros nos permite verificar que no quinquênio inicial de publicação do Boletim a ênfase foi dada aos conteúdos de geometria a serem trabalhados com os alunos e o destaque às demonstrações foi considerável neste período. Nos próximos cinco anos - 1981-1985 - destacam-se os comentários e considerações relativos à importância da geometria, trazendo junto a estas argumentações proposta de atividades, relação de exercícios, experiências de ensino para professores e, também, atrelado a esta importância o destaque a "um método que permite a demonstração" (n.17, $1982^{8}$ ). No quinquênio que vai do ano de 1986 ao ano de 1990 a importância da geometria é a tônica das produções analisadas e junto a ela são indicadas diversas propostas de atividades. Foi neste quinquênio que tivemos a primeira produção que traz informações a respeito do desenvolvimento do raciocínio em geometria e aponta as dificuldades apresentadas pelos alunos em seu aprendizado. As remissões às demonstrações também têm seu lugar nos comentários dos autores dos documentos analisados e a teoria de Van Hiele começa a ter seu espaço no desenvolvimento das propostas. No período que vai de 1991 a 1995 - é mantido o discurso a respeito da importância da geometria, contudo, foi neste período que identificamos essa importância do ensino de geometria relacionada à formação do educador. Foi também nesse quinquênio que a teoria de Van Hiele foi mais referenciada. Além desses destaques, tivemos nesses cinco anos as primeiras considerações relativas ao uso de softwares durante a apresentação das propostas de ensino da geometria. Nos próximos cinco anos - 1996-2000 - a ênfase à importância do ensino e da aprendizagem da geometria ainda continua sendo destacada, assinalando a relação geometria e computador, as demonstrações, relacionando algumas dificuldades apresentadas pelos alunos aprendizes e trazendo propostas para licenciandos em matemática. No quinquênio que vai do ano de 2001 ao ano de 2005 - a importância novamente é destacada - contudo o foco neste período foi dado ao ensino da geometria e juntamente a estas proposições de situações de ensino temos o modelo de Van Hiele, os softwares,

8. Para não incluirmos este artigo citado nas referências duplicando a indicação, optamos por remeter tal indexação à nossa lista dos 93 artigos - sendo este o de número 17. 
as geometrias não euclidianas, o método axiomático e as demonstrações (agora vistas pela perspectiva das limitações e das dificuldades apresentadas pelos alunos para o seu aprendizado). Por fim, temos o período que vai de 2006 a 2010 - neste momento o discurso converge para os recursos computacionais versus as situações de ensino e de aprendizagem.

Diante deste movimento interpretativo e se tivéssemos que resumir em poucas palavras como a geometria está caracterizada nas publicações desse periódico nos 35 anos analisados, concluiríamos que os autores em suas produções buscaram enfatizar a importância da geometria, apresentando, para isso, listagens de conteúdos fundamentais para serem trabalhados com alunos da educação básica e com professores em formação inicial e continuada, além de trazerem em suas propostas relações de atividades que poderiam ser utilizadas nessas e em outras situações de ensino. Por isso as categorias emergentes desse corpus investigado são a importância da geometria, os conteúdos a serem trabalhados e propostas de atividades.

Finalizamos a análise, destacando que o que aqui apresentamos é uma forma de leitura e de interpretação construída por nós, com o objetivo de caracterizar o que foi publicado sobre geometria nesses 35 anos de edição do Boletim Gepem. Fica evidente que não partimos de algo determinado, definido a priori, mas construímos um perfil para esse campo mediante o que está materializado nos artigos publicados ao longo desses 35 anos (1976-2010).

\section{Considerações Finais}

Uma das dificuldades inerentes a esses movimentos de pesquisa que buscam inventariar produções científicas, diz respeito à forma e ao formato com que essas produções eram apresentadas. E que nem sempre continham alguns elementos que auxiliam em sua identificação, como as palavras-chave, hoje de suma importância para as buscas ágeis realizadas em ambientes digitais e, antigamente, inexistentes nos artigos e que podem sustentar a essencialidade incutida pelo próprio autor ou autores da produção, ou seja, os próprios idealizadores dos artigos indicam quais palavras, para eles, são representativas de sua produção.

Sobre essas colocações temos algumas considerações e exemplificações a comentar: quanto à estrutura de apresentação das produções, destacamos que inicialmente elas não traziam resumo, palavras-chave, abstract, keywords e conclusão. O primeiro artigo a apresentar resumo, palavras-chave, abstract, keywords, desenvolvimento e conclusão, é um artigo do ano de 1999, na revista de número 35. Afora esta produção, o primeiro artigo de autoria nacional a apresentar todas estas características é do ano de 2002, da revista de número 40. 
As considerações a que chegamos ao final desta caminhada investigativa mostra-nos o movimento realizado por pesquisadores e/ou profissionais atuantes da área de Educação Matemática ao longo de três décadas e meia, no que diz respeito a seus investimentos com relação à geometria. Essa caracterização do que foi realizado até o ano de 2010 contribui com as projeções que idealizamos para os movimentos do nosso grupo de pesquisa com relação às ações que pretendemos realizar integrado à geometria e à formação de professores.

A relação dos 93 artigos pode - se vista em outra perspectiva - apontar as tendências para a área, e neste caso teríamos como indicativo a relação geometria e tecnologias e a recuperação do que foi deixado de ser trabalhado com relação às demonstrações. Enfatizamos ainda que se a abordagem do método demonstrativo fosse retomada em propostas vindouras, iria suprir diversas lacunas apontadas por esses autores em suas publicações no Boletim Gepem.

Outra possibilidade que vemos com esse levantamento e a sistematização dessas informações é que a geometria não está sendo objeto de estudo em configurações informais de aprendizagem, isto é, nenhuma das proposições dos autores cujas publicações foram analisadas abre a possibilidade do aprendizado da geometria em ambientes informais (fora do contexto escolar) - em museus de ciência e tecnologia, por exemplo. O que aponta para uma possibilidade investigativa interessante e frutífera.

\section{Referências ${ }^{9}$}

ANDRADE, E. C. Análise de uma proposta aplicada em sala de aula sobre geometria com foco na demonstração. 2011. 159p. Dissertação (Mestrado em Ensino de Ciências e Educação Matemática) - Universidade Estadual de Londrina, Londrina, 2011.

BARDIN, L. Análise de conteúdo. Lisboa: Edições 70, 1977, 3.ed., 2004.

BRASIL. Parâmetros Curriculares Nacionais: Matemática. Secretaria de Educação Fundamental. Brasília: MEC, 1998.

FAINGUELERNT, E. K. O Ensino de Geometria no $1^{\circ}$ e $2^{\circ}$ Graus. Educação Matemática em Revista, n.4, p.45-52, 1995. Edição Especial.

9. Optamos por relacionar todos os artigos analisados na apresentação dos dados. Em virtude desta opção não os relacionamos novamente nas referências que compõem essa produção. 
LORENZATO, S. Por que não Ensinar Geometria? Educação Matemática em Revista, n.4, p.3-13, 1995. Edição Especial.

MORAES, R.; GALIAZZI, M. C. Análise Textual Discursiva. Ijuí: Ed. Unijuí, 2007.

OLIVEIRA, R. de; BAIRRAL, M. A.; REIS, R. M. M. Um estudo sobre a educação matemática publicada nos 30 anos do Boletim Gepem. Boletim Gepem, n.48, p.23-84, 2006.

ROMANOWSKI, J.; ENS, R. As pesquisas denominadas do tipo "Estado da Arte" em Educação. Diálogo Educacional, v. 6, n.19, p.37-50, 2006.

Submetido em outubro de 2012

Aprovado em janeiro de 2013 